\title{
Adverse Effects of Khat (Catha edulis) Chewing in Yemeni Adults: A Case-Control Study
}

\author{
Khaled Abdul-Aziz Ahmed ${ }^{1}$, Talal Helal Abdoh' ${ }^{2}$ Husni S. Farah ${ }^{1}$, Talal Salem Al-Qaisi ${ }^{3}$, Khalid M. Al- \\ Qaisi $^{3}$, Jehad F. Alhmoud ${ }^{3}$ \\ ${ }^{1}$ Associate Professor; Department of Medical Laboratory Sciences, Faculty of Allied Medical Sciences, Al-Ahliyya \\ Amman University, Amman 19328, Jordan, ${ }^{2}$ Tutor; Department of Medical Microbiology, Faculty of Science, \\ Ibb University, Ibb, Yemen, ${ }^{3}$ Assistant Professor; Department of Medical Laboratory Sciences, Faculty of Allied \\ Medical Sciences, Al-Ahliyya Amman University, Amman 19328, Jordan
}

\begin{abstract}
Background: Khat is the common name for the plant Catha edulis. The leaves and buds of Khat are chewed and their use is an established cultural tradition for many social situations in Yemen. Traditionally, Khat has been frequently chewed on social occasions, in public spaces or designated rooms in private homes. The medical and psychosocial impacts of khat chewing have been reported previously. However, the effect of chewing Khat on some biochemical and hematological parameters needs further investigation.

Objectives: This study was carried out to investigate the effect of Khat chewing on a number of biochemical and hematological parameters in a population-based groups.

Materials and Methods: One hundred and eighty eight $(n=188)$ subjects who have completed the questionnaire were included in this study. Ninety eight $(n=98)$ subjects among these were Khat chewers and ninety $(n=90)$ were non-chewers of Khat. Blood samples were collected from each subject in the study to measure uric acid, rheumatoid factor (RF) and complete blood cell (CBC) counts.

Results: It has been shown that joint pain and kidney disease were significantly more prevalent in Khat chewers than Khat non-chewers. Uric acid levels were markedly higher in Khat chewers than Khat nonchewers, while differences in RF levels between the two groups were not significant. Although RBCs indices showed no significant difference among the study groups, a statistical significance in the white blood cells (WBCs), lymphocytes, and platelets counts was observed.
\end{abstract}

Conclusion: The present study strongly suggeststhat Khat chewing had an adverse effect on the development of arthritis and kidney diseases. Moreover, altered immune defence mechanisms due to Khat chewing have also been documented in this study.

Keywords: Khat chewing, Catha edulis, arthritis, kidney diseases

\section{Corresponding author:}

\section{Dr. Khaled Abdul-Aziz Ahmed}

Associate Professor, Department of Medical Laboratory Sciences, Faculty of Allied Medical Sciences, AlAhliyya Amman University, Amman 19328, Jordan Email Addresses: k.ahmed@ammanu.edu.jo,khaaah@ gmail.com, Mobile phone.: +962795101872

\section{Introduction}

Khat (Catha edulisForsk) has been grown for use as a stimulant for centuries in different countries including Ethiopia, Somalia, Yemen, Kenya, Uganda, the Congo, Zambia, and South Africa ${ }^{1,2}$. The chewing of Khat leaves for social and psychological reasons has been practiced for many centuries and its use has been gradually 
expanded to many countries worldwide ${ }^{3,4}$. In Yemen, it has become aserious national concern because of its widespread use.The adverse effects of Khat chewing habit on different human body systems were extensively reviewed ${ }^{5-7}$.In their literature review, Rassool and AbouSaleh, have suggested that Khat affects the digestive, respiratory, endocrine and cardiovascular systems ${ }^{7}$.The quality of life of Khat chewers and non-Khat chewers was assessed and compared using a health survey. The investigatorsshowed that lower quality of life and lower socioeconomic status are correlated with Khat chewing ${ }^{8}$.

Khat-chewing has been reported as a harmful activity by several studies around the world on the basis of health and socio-economic consequences as reviewed by Karunamoorthi and colleage ${ }^{9}$. However, it can lead to health consequences like oral infection if it is chewed excessively and in large quantities ${ }^{10}$.Some studies indicated that hypertension, myocardial infarction, and liver diseases are among the major health consequences of Khat chewing ${ }^{11-13}$. It has been documented that Khat intake results in improved energy levels and alertness, enhances imaginative ability and the capacity to associate thoughts, and improves the ability to communicate ${ }^{14}$.It has been reported that psychosis was induced by Khat ${ }^{15}$. A large survey among Yemeni adults done by Numan has excluded any correlation between Khat chewing and psychopathological alterations ${ }^{16}$. Although Khat is used as a stimulant drug that increases brain awareness, it has an adverse effect on the body physiology and causes many diseases. The effect of Khat chewing on the development of kidney disease and arthritis has not been studied wellon a population that commonly use Khat. Therefore, the purpose of this prospective study was to evaluate whether arthritis and kidney disease are developed by Khat use. The changes in immune defense parameters due to Khat chewing are also evaluated.

\section{Materials and Methods}

\section{Study population}

A total of 222 adults who met the eligibility criteria were selected, of which 34 were smokers and were thus excluded from the study. The others 188 subjects have completed both the questionnaire and measurements. Among the 188 study participants, 98 were Khat chewers (group1) and 90 were non-chewers as controls (group 2). Khat chewers and non-chewers were randomly selected from different populations including students, teachers, and farmers from different areas in Ibbprovince of Yemen. Other participants in the study were selected from patients who regularly attending the Internal Medicine Clinics at Jeblah Hospital and other health centers at Ibb city. All diseases stated in this study were diagnosed by specialists in Jeblah Hospital or other health centers. Each participant has been interviewed and completed a questionnaire. Smokers, former smokers, pregnant women, diabetes and participants with age of 70 and above were excluded from the study. The two groups were matched for different parameters including age, sex, nutritional habits, and all the exclusion criteria.

\section{Sample collection}

Blood samples were taken in the morning between 8:00 and 10:00 a.m. from all participants. Samples were collected from each participant in two tubes, $5 \mathrm{ml}$ in EDTA $(1 \mathrm{mg} / \mathrm{ml})$ tube and $5 \mathrm{ml}$ in an anticoagulant-free tube. The EDTA anticoagulated blood was used for analysis of Complete Blood Cell count (CBC) by hematology analyzer. Blood samples in the anticoagulant-free tube were centrifuged at $3000 \mathrm{xg}$ for 10 minutes at room temperature within $90 \mathrm{~min}$ after collection and the serum was stored in eppendorf tubes at $-20^{\circ} \mathrm{C}$ for uric acid and rheumatoid factor analysis.

\section{Laboratory measurements}

$\mathrm{CBC}$ was analyzed by hematology analyzer (CBC analyzer, KX-21N, Germany). Uric acid concentration in the serum was assessed using reagent kit obtained from Spinreact (S.A. Ctra Santa Coloma, Spain). Rheumatoid Factor (RF) was estimated in the serum of the study population using RF-latex supplied by Spinreact (S.A. Ctra Santa Coloma, Spain). The RF-latex is a slide agglutination test for the qualitative and semiquantitative detection of RF in human serum. Polystyrene latex particles coated with human gammaglobulin are agglutinated when mixed with samples indicting that the RF is present in the serum (cut-off $<8 \mathrm{IU} / \mathrm{ml}$ ). The approximate RF concentration in the individual sample was calculated. 


\section{Statistical Analysis}

The qualitative data were expressed as a number and percentage. Chi-square was used as a test of significance for qualitative data. Student t-test was used to study significance of quantitative data. Significance was calculated according to the $P$ value. $P$ value of less than 0.05 is considered significant while $\mathrm{P}$ value more than 0.05 considered insignificant. Statistical analysis was performed by using SPSS software version 16 .

\section{Results}

1. Frequency of different parameters in Khat chewers and non-chewers

The age of Khat chewers and non- chewers groups are $33.6 \pm 11.7$ and $31.0 \pm 13.6$ years $(P=0.16)$,
Medico-legal Update, July-September 2021, Vol.21, No. 3

333 respectively.Of the study groups, $36.70 \%$ were males and $63.30 \%$ were females.As shown in Table 1 , there were no significant difference in the frequency of study subjects in different parameters including body mass index (BMI), diuretics use, hypertension, and rheumatoid factor results among both groups. However, most of the study participants are normotensives $(88.4 \%)$ and have normal weight $(56.6 \%)$. The percentages of individuals who are having arthritisand kidney diseases were significantly more in Khat chewers than Khat non-chewerssubjects; $40.9 \%$ vs. $26.3 \%, P=0.001$ and $36.6 \%$ vs. $24.2 \%, P=0.011$, respectively. Furthermore, the percentages of Non-steroidal anti-inflammatory drugs (NSAID) use in Khat chewers were increased significantly as compared with Khat non-chewers.

Table 1. Frequency of clinical characteristics in Khat chewers and non-chewers groups

\begin{tabular}{|c|c|c|c|c|c|}
\hline & \multicolumn{2}{|c|}{$\begin{array}{c}\text { Khat chewers } \\
\text { (No. }=98)\end{array}$} & \multicolumn{2}{|c|}{$\begin{array}{c}\text { Khat non-chewers } \\
(\text { No. }=90)\end{array}$} & \multirow{2}{*}{$P$-value* } \\
\hline & Frequency & Percent & Frequency & Percent & \\
\hline Gender (males/females) & $33 / 65$ & $17.6 / 34.6$ & $36 / 54$ & $19.1 / 28.7$ & 0.369 \\
\hline $\begin{array}{l}\text { Plant food } \\
\text { 1-4 times/day } \\
5-7 \text { times/day }\end{array}$ & $\begin{array}{l}81 \\
17\end{array}$ & $\begin{array}{c}43.1 \\
9.0\end{array}$ & $\begin{array}{l}69 \\
21\end{array}$ & $\begin{array}{l}36.7 \\
11.2\end{array}$ & 0.726 \\
\hline $\begin{array}{c}\text { Animal food } \\
\text { nothing/week } \\
1 \text { time/week } \\
\text { 2-4 times/week } \\
\text { 5-7 times/week }\end{array}$ & $\begin{array}{c}7 \\
73 \\
14 \\
4\end{array}$ & $\begin{array}{c}3.7 \\
38.8 \\
7.4 \\
2.1\end{array}$ & $\begin{array}{c}13 \\
60 \\
8 \\
9\end{array}$ & $\begin{array}{c}6.9 \\
31.9 \\
4.3 \\
4.8\end{array}$ & 0.098 \\
\hline $\begin{array}{c}\text { BMI groups }\left(\mathrm{kg} / \mathrm{m}^{2}\right) \\
\text { Underweight }(<18.5) \\
\text { Normal }(18.5-24.9) \\
\text { Overweight }(25-29.9) \\
\text { Obese }(\geq 30)\end{array}$ & $\begin{array}{c}13 \\
50 \\
27 \\
8\end{array}$ & $\begin{array}{c}6.9 \\
26.6 \\
14.4 \\
4.3\end{array}$ & $\begin{array}{l}10 \\
53 \\
17 \\
10\end{array}$ & $\begin{array}{c}5.3 \\
28.2 \\
9.0 \\
5.3\end{array}$ & 0.521 \\
\hline Arthritis & 76 & 40.9 & 49 & 26.3 & 0.001 \\
\hline Kidney disease & 68 & 36.6 & 45 & 24.2 & 0.011 \\
\hline Diuretics users & 56 & 54.9 & 40 & 39.2 & 0.687 \\
\hline NSAID users & 59 & 36.0 & 29 & 17.7 & 0.001 \\
\hline Hypertension & 13 & 7.9 & 6 & 3.7 & 0.117 \\
\hline ositive Rheumatoid Factor & 14 & 7.5 & 10 & 5.3 & 0.533 \\
\hline
\end{tabular}

* Based on Chi-Square test. NSAID= Non-steroidal anti-inflammatory drugs. 
2. Laboratory characteristics of the study populations

The major clinical and laboratory characteristics of the study groups are summarized in Table 2. A statistical significance was observed in the WBCs, lymphocytes, and platelets counts among the study groups. It has also been revealed in that uric acids levels were markedly higher in Khat chewers than Khat non-chewers, 5.04 \pm 1.83 vs. $4.12 \pm 1.39, P<0.001$ (Table 2). Furthermore, Figure 1shows that the increased uric acids values were significantly and positively correlated with duration of Khat chewing $(R=0.323, P=001)$. There were no significant differences in systolic blood pressure, diastolic blood pressure, and $\mathrm{RBCs}$ indices (PCV, MCV, $\mathrm{MCH}$, and $\mathrm{MCHC}$ ) between the study groups.

Table 2: Clinical and laboratory characteristics of the study groups

\begin{tabular}{|c|c|c|c|}
\hline & Khat chewers & Khat non-chewers & $P$ value* \\
\hline Uric acid (mg/dl) & $5.14 \pm 1.73$ & $4.09 \pm 1.19$ & $<0.001$ \\
\hline $\operatorname{RBCs}\left(\mathrm{X} 10^{12} / 1\right)$ & $5.05 \pm 0.89$ & $5.09 \pm 0.78$ & NS \\
\hline Hemoglobin $(\mathrm{g} / \mathrm{dl})$ & $14.25 \pm 2.57$ & $14.40 \pm 2.33$ & NS \\
\hline WBCs $\left(\mathrm{X} 10^{9} / 1\right)$ & $7.19 \pm 2.58$ & $6.02 \pm 2.14$ & 0.001 \\
\hline Lymphocytes $\left(\mathrm{X} 10^{9} / 1\right)$ & $3.39 \pm 1.23$ & $4.01 \pm 1.22$ & 0.001 \\
\hline PCV (1/1) & $0.42 \pm 0.07$ & $0.42 \pm 0.06$ & NS \\
\hline $\operatorname{MCV}(f l)$ & $84.3 \pm 15.4$ & $83.47 \pm 0.31$ & NS \\
\hline $\mathrm{MCH}(\mathrm{pg})$ & $28.74 \pm 0.48$ & $28.45 \pm 0.69$ & NS \\
\hline $\mathrm{MCHC}(\mathrm{g} / \mathrm{dl})$ & $33.99 \pm 0.83$ & $34.05 \pm 0.62$ & NS \\
\hline Platelets $\left(\mathrm{X} 10^{9} / 1\right)$ & $283.3 \pm 84.4$ & $258.5 \pm 64.3$ & 0.024 \\
\hline Systolic blood pressure $(\mathrm{mmHg})$ & $110.2 \pm 20.5$ & $108.3 \pm 19.6$ & NS \\
\hline Diastolic blood pressure (mmHg) & $72.6 \pm 13.5$ & $71.7 \pm 11.3$ & NS \\
\hline
\end{tabular}

Values are mean \pm standard deviation (SD). *Significantly different between Khat chewing and non-chewing groups if $P<0.05$. NS; the difference between groups is not significant. PCV; packed cell volume, MCV; Mean cell (or corpuscular) volume, $\mathrm{MCH}$; Mean cell hemoglobin, MCHC; Mean cell hemoglobin concentration. 


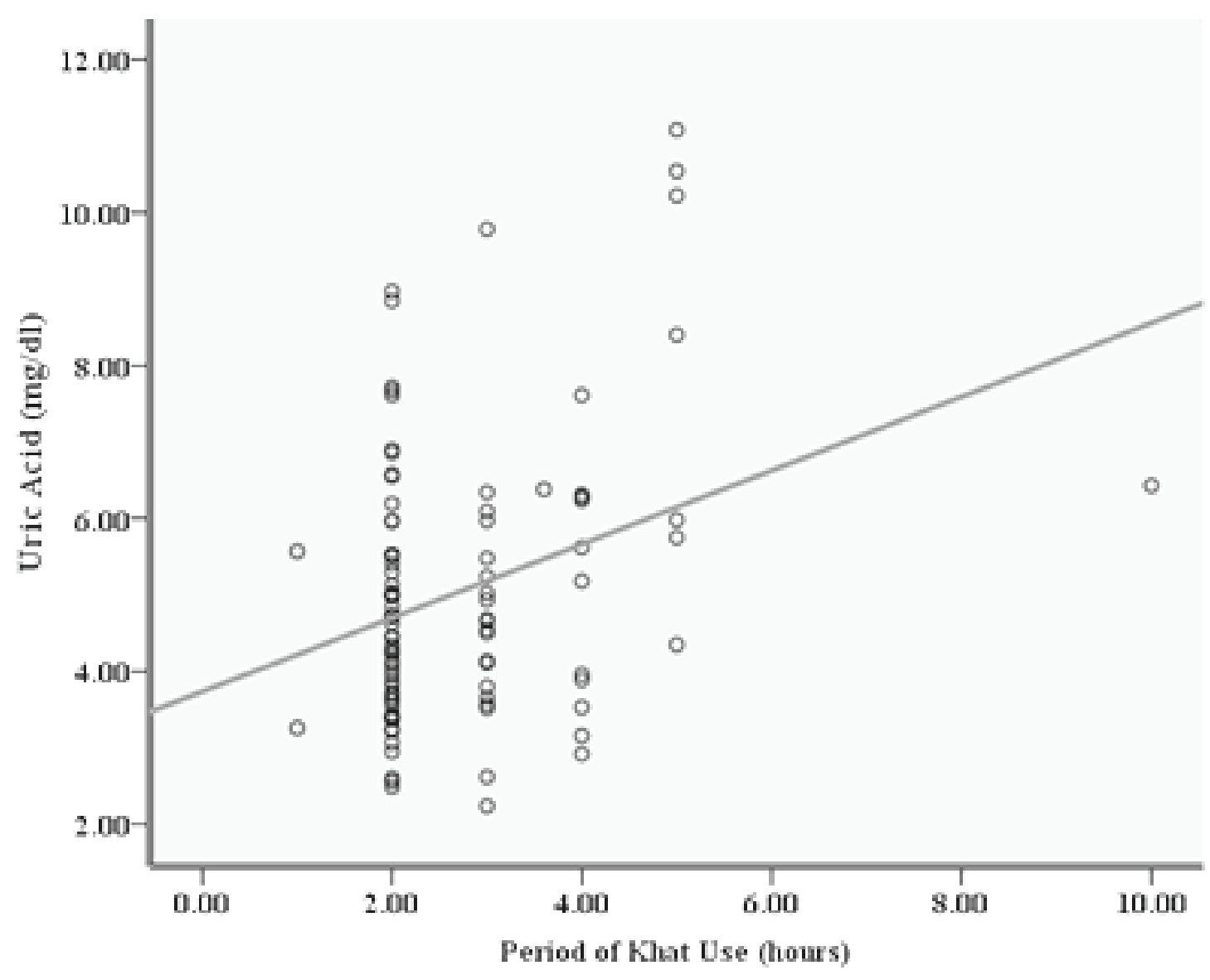

Figure 1. Correlation analysis between Khat chewing period (hours/day) and uric acid levels showing positive correlation $(P=\mathbf{0 . 0 0 1})$.

\section{Discussion}

Khat chewing is a common social habit in Yemen that has been practiced for decades by both men and women and sometimes even children for a few hours per day, and in many cases it is a lifetime habit. The Khat chewing process leads to the storage of Khat leaves in the mouth until the cheek expands to look like a ball of different sizes from person to another.Many adverse health changes were reported in the literature. For example, adverse effects of this habit on various human body systems such as liver ${ }^{17}$, central nervous system, and digestive system were extensively investigated ${ }^{18-20}$. Furthermore, the association of Khat use with oral and dental diseases has been reported, with particular emphasis on its link with oral keratotic white lesions and oral cancer ${ }^{21}$.In the present study, we examined the association of Khat chewing with arthritis and hematological parameters changes.
The current study suggests for the first time, using a case-control study design, that high prevalence of arthritis and increased uric acid levels were seen in longterm Khat chewing at the population level. There was no statistical significance in the percentages of using meat-containing meal among the study groups. In both study groups, $70.8 \%$ had once a week animal food meal and $11.7 \%$ had 2-4 times per week. Therefore, the effect of animal food on the accumulation of uric acid in the joints was excluded by analysis.

Our results also revealed a higher prevalence of kidney disease due to Khat chewing. The concurrent increase in uric acids with kidney disease has been recently investigated in patients with diabetes ${ }^{22}$. The investigators observed that patients with hyperuricemia and diabetes had a higher systolic blood pressure and higher BMI levels. Our study found thatmost of the study population had normal systolic blood pressure and 
similar BMI values with a high prevalence of normal weight individuals. Therefore, association of increased uric acid values and kidney diseases in Khat chewers compared to Khat non-chewers suggests that chronic use of Khat may have a more pronounced impact and not other confounding factors. Our results are not in agreement with the previous study that exclude the occurrence of kidney damage among Khat chewers ${ }^{23}$.In addition, the findings of this study revealed normal and insignificant difference in diastolic blood pressure between the study groups. The findings in the present study contradict the earlier study of Getahunand colleagues, which showed a correlation between Khat chewing and elevated diastolic blood pressure ${ }^{24}$.

Besides, we examined the effect of daily Khat chewing on hematological parameters. There was no significant differences in the studied red blood cells indices. However, lymphocytesand platelets count were significantly different and it is suggested to be due to Khat chewing. In addition, our results also revealed that WBCs count was significantly higher in Khat chewers than non-chewers. These results can be explained for different reasons, such as psychological stress or poisoning that may explain the increased leukocytes seen in Khat chewers. A potential synergistic association between Khat use and stress disorders was previouslydocumented ${ }^{25,26}$. Some other health problems include sleeping problems, feeling tired and/or depressed in the morning after a Khat-chewing session, loss of appetite, and feeling the need to chew Khat again ${ }^{27}$.

In order to make them grow more and rapidly, Yemeni farmers usually apply unauthorized chemical pesticides on Khat bids. Since the use of unapproved chemical pesticides for Khat is uncontrolled, consumers started getting affected by these harmful chemicals and thus face several health problems. The poisoning that happens with the use of Khat may therefore not be due to Khat itself, but rather to theincreased risk of these toxic pesticides being swallowed, which may be the cause of the increased leukocytesobserved in individuals chewing $\mathrm{Khat}^{28}$.It has also been shown that the lymphocytes count was lower in Khat chewers compared to Khat non-chewers. Earlier studies found that Ethiopians have lower lymphocyte counts compared to Dutch ${ }^{29,30}$.
To our knowledge, this is the first study to report the association of low lymphocytes with Khat chewing in Yemeni population. The first explanation for these findings is that low lymphocytes counts in Yemeni Khat chewing individuals could be related to loss of appetite following Khat chewing or poor nutritional status. In fact, malnutrition depresses immune functions ${ }^{31}$ and malnutrition is prevalent in Yemeni population because of lack of appetite or poverty. Cathine is an alkaloid isolated from Khat with similar amphetamine-like effects on the central nervous system. It has been reported by Connor that amphetamines may have an immunosuppressive role ${ }^{32}$. These findings indicate that actually has the ability to dramatically alter the immune response.

\section{Conclusion}

Our study revealed that Khat chewing may contribute to arthritis as confirmed by increased uric acid levels. A considerably lower proportion of animal food among Khat chewers suggests that the accumulation of uric acid in the joint was not due to massive protein metabolism, rather may be due to the way the chewers sit during Khat use. The findings also showed that frequentKhat chewing and increased WBCs and decreased lymphocytes counts are associated, indicating that Khat has an adverse effect on the function of the immune system. The effect of Khat on WBCs and lymphocytes counts, however, is intriguing and deserves further investigations. Having recognized Khatchewing problems and their adverse effects on health and the socio-economic development of the country, educational programs for the prevention and control of these adverse effects in the population need to be started before implementing legislative measures or issuing laws to prohibit Khat use in the community of Yemen.

Conflict of Interest: All authors do not have a conflict of interest to declare.

Source of Funding: self-funding.

Ethical Clearance: The study was approved by Ibb University, Ibb, Yemen.

Acknowledgments: The corresponding author would like to thank International Institute of 
EducationScholar Rescue Fund program (IIE-SRF) for awarding the fellowship at Al-Ahliyya Amman University. The authors would like to thank Al-Ahliyya Amman University for paying the publication charge of this paper.

\section{References}

1. Glenice C, Hagen R. Adverse effects of khat: a review. Advances in Psychiatric Treatment. 2003;9:456-463.

2. Balint EE, Falkay G, Balint GA. Khat-a controversial plant. Wien KlinWochenschr. 2009;121:604-614.

3. Weir S. Qat in Yemen: consumption and social change.British Museum Publications, London, 1985.

4. Nencini P, Grassi MC, Botan AA, Asseyr AF, Paroli E. Khat chewing spread to the Somali community in Rome. Drug and Alcohol Dependence. 1989; 23:255-258.

5. Al-Hebshi N, Skaug N. Khat (Catha edulis)an updated review. Addiction Biology. 2005;10(4):299-307.

6. Hassan NA, Gunaid AA, Murray Lyon IM. Khat [Catha edulis]: health aspects of khat chewing. Eastern Mediterranean Health Journal. 2007;13(3):706-718.

7. Rassool GH. The Flower of "Artificial Paradise": The Use and Misuse of Khat (Qat)-a Review of the Literature. Arab Journal of Psychiatry. 2000;11(1):1-9.

8. Sheikh KA, El-Setouhy M, Yagoub U, Alsanosy R, Ahmed Z. Khat chewing and health related quality of life: cross-sectional study in Jazan region, Kingdom of Saudi Arabia. Health and Quality of Life Outcomes. 2014;12(1):1-10.

9. Karunamoorthi K, Udeani G, Babu SM, Mossie A. Psychopharmacosocial Aspects of Catha edulisForsk (Fam. Celastraceae). African Journal of Pharmaceutical Sciences and Pharmacy. 2010;1:112-129.

10. Ali AA, Al-Sharabi AK, Aguirre JM, Nahas R. A study of 342 oral keratotic white lesions induced by qat chewing among 2500 Yemeni. Journal of Oral Pathology \&Medicine. 2004;33(6):368-372.
11. Tesfaye F, Byass P, Wall S, Berhane Y, Bonita R. Peer reviewed: Association of smoking and Khat (Catha edulisForsk) use with high blood pressure among adults in Addis Ababa, Ethiopia, 2006. Preventing Chronic Disease. 2008;5(3):1-11.

12. Al-Motarreb A, Briancon S, Al-Jaber N, A-Adhi B, Al-Jailani F, Salek MS, Broadley KJ. Khat chewing is a risk factor for acute myocardial infarction: a case-control study. British Journal of Clinical Pharmacology. 2005;59(5):574-81.

13. Roelandt P, George C, d'Heygere F, Aerts R, Monbaliu D, Laleman W,et al. Acute liver failure secondary to khat (Catha edulis)-induced necrotic hepatitis requiring liver transplantation: Case report. In Transplantation proceedings. Elsevier Inc.; 2011;43(9):3493-3495.

14. Ihunwo AO, Kayanja FI, Amadi-Ihunwo UB. Use and perception of the psychostimulant, khat (cathaedulis) among three occupational groups in south western Uganda. East African Medical Journal. 2004;81(9):468-473.

15. Yousef G, Huq Z, Lambert T. A study of khat induced psychosis. European Psychiatry. 1996;11(S4):400s.

16. Numan N. Exploration of adverse psychological symptoms in Yemeni khat users by the Symptoms Checklist-90 (SCL-90). Addiction. 2004;99(1):6165.

17. Mahamoud HD, Muse SM, Roberts LR, Fischer PR, Torbenson MS, Fader T. Khat chewing and cirrhosis in Somaliland: Case series. African Journal of Primary Health Care \& Family Medicine. 2016;8(1):e1-4.

18. Kalix P. Khat: a plant with amphetamine effects. Journal of Substance Abuse Treatment. 1988;5(3):163-9.

19. Halket JM, Karasu Z, Murray-Lyon IM. Plasma cathinone levels following chewing Khat leaves (cathaedulisforsk.). Journal of Ethnopharmacology. 1995;49(2):111-113.

20. Gunaid AA, EL-Khally FM, Hassan NA, MurrayLyon IM. Chewing Khat leaves slows the whole gut transit time. Saudi Medical Journal. 1999;20:444447.

21. Al-Maweri SA, Warnakulasuriya S, Samran A. 
Khat (Catha edulis) and its oral health effects: An updated review. Journal of Investigative and Clinical Dentistry. 2018;9(1):e12288.

22. Zoppini G, Targher G, Chonchol M, Ortalda V, Abaterusso C, Pichiri I, et al. Serum uric acid levels and incident chronic kidney disease in patients with type 2 diabetes and preserved kidney function. Diabetes Care. 2012;35:99-104.

23. Mworia CM, Kinge W, Kahato M, Mwamisi J. Effects of Catha edulis on kidney and liver function among chewing adults in Meru County, Kenya. East African Medical Journal. 2016;93(7):261-265.

24. Getahun W, Gedif T, Tesfaye F. Regular Khat (Catha edulis) chewing is associated with elevated diastolic blood pressure among adults in Butajira, Ethiopia: a comparative study. BMC Public Health. 2010;10(1):1-8.

25. Odenwald M. Chronic khat use and psychotic disorders: a review of the literature and future prospects. Sucht. 2007;53(1):9-22.

26. Hoffman R, Al'Absi M. Khat use and neurobehavioral functions: suggestions for future studies. Journal of Ethnopharmacology. 2010;132(3):554-563.

27. Patel SL, Murray R, Britain G. Khat use among Somalis in four English cities. Home Office,
London. 2005.

28. Date J, Tanida N, Hobara T. Khat chewing and pesticides: A study of adverse health effects in people of the mountainous areas of Yemen. International Journal of Environmental Health Research. 2004;14(6):405-414.

29. Tsegaye A, Messele T, Tilahun T, Hailu E, Sahlu T, Doorly R, Fontanet AL, de Wit TFRinke de Wit TF. Immunohematological reference ranges for adult Ethiopians. Clinical and Diagnostic Laboratory Immunology. 1999;6(3):410-414.

30. Kassu A, Tsegaye A, Petros B, Wolday D, Hailu E, Tilahun T, et al. Distribution of lymphocyte subsets in healthy human immunodeficiency virus-negative adult Ethiopians from two geographic locales. Clinical and Diagnostic Laboratory Immunology. 2001; 8:1171-1176.

31. Chandra RK. Nutrition and immunology: From the clinic to cellular biology and back again. Proceedings of the Nutrition Society. 1999;58:681683.

32. Connor TJ: Methylenedioxymethamphetamine (MDMA, 'Ecstasy'): A stressor on the immune system. Immunology. 2004;111:357-367. 